\title{
Reliability and service in the power industry
}

\author{
Yulia Zhilkina $^{1^{*}}$, and Dmitry Vodennikov ${ }^{2}$ \\ ${ }^{1}$ Candidate of economic sciences, Assets management Department, Federal Grid Company of Unified Energy System, Moscow, Russia \\ ${ }^{2}$ Deputy Chairman of the board- Chief Engineer, Federal Grid Company of Unified Energy System, Moscow, Russia
}

\begin{abstract}
Development of scientific and technical progress, introduction of new technologies promotes specialization and isolation of the highly professional service markets in economy. In power industry this market is the most natural object of development of the market relations. Nevertheless, today service structures carry out mainly internal orders on repair of the equipment of the power enterprises in the status of affiliated dependent or indirectly affiliated organizations. The principles of formation and transition to service considering a current state of power industry the main requirements imposed to service activity, her potential and providing balance of interests of market subjects are developed (commercial, reliability and energy efficiency). The main models of the organization of service are proved and recorded. The realized models of service will allow reaching a positive effect.
\end{abstract}

\section{Background}

Development of scientific and technical progress, introduction of new technologies promotes specialization and isolation of the highly professional service markets in economy. In power industry this market is the most natural object of development of the market relations. Nevertheless, today service structures carry out mainly internal orders on repair of the equipment of the power enterprises in the status of affiliated dependent or indirectly affiliated organizations.

Despite the considerable volume of researches in the field of the organization of service in a power network complex, a set of aspects in the field remain insufficiently studied, both in foreign, and in domestic science. The main theoretic-methodological problem is absence uniform for subjects of a power market of strategy of service which taking into account national peculiarities of power industry could provide forward development of all branch in general.

\section{Reliability and service}

The all technical sense of the concept «reliability» [1] is a property of an object to keep steadily in the set limits of value of all parameters characterizing ability of an object to perform the required functions in the set modes and conditions of its application, maintenance, storage and transportation. If to consider power industry as uniform technical system, then reliability should be considered one of technical properties of such system.

Reliability in power industry consists of two components - system reliability and reliability of separate units of equipment. Universal solution of the specified problems is such approach to operation and the maintenance of the equipment at which each unit of equipment is considered as continuous risk factor for business challenges of the enterprise. A main objective of activities for the maintenance of the equipment is the greatest possible reduction of risk in the available conditions and restrictions. At such formulation of the question management of reliability turns from the providing expensive activity into the tool of the solution of the current business challenges - increases have arrived due to more effective use of the equipment, decrease in laid on expenses at preservation of load of the equipment.

Reach compromise between economy on costs of the equipment and desire to avoid accidents, idle times and losses from them is the main administrative problem connected with ensuring reliability.

The situation is aggravated with objective factors as: serious wear of fixed assets, age and technological heterogeneity, decrease in professional level of the operating and repair personnel, decline in quality of the made spare parts and accessories, the operation of the equipment in the limit and ultra-boundary modes of loading which was outdate, not answering to realities regulatory and procedural base of processes of operation, service and repairs. It's possible to solve the problems stated considerably above by modernization of technological base, with transition to service.

\subsection{Service advantages}

The analysis of theoretical approaches to the organization of service of the electrotechnical equipment in power industry has shown that today in science and practice there is no standard branch definition of service. There are many definitions of the concept "service" which give both lawyers, and economists. The Ministry

Corresponding author: zhilkina-yv@fsk-ees.ru 
of Energy of the Russian Federation on the official site is given definition of service: service as a commercial product is provided by specialized companies who are ready to offer the best ready-made solution to the task of reducing costs, which, with relatively small investments, can give the best result in the shortest possible time.

One of the most essential advantages of service is the flexibility and competent risk management. Transferring a part of the business processes of service company, also the accompanying risks are automatically transferred. At the same time the service company having a number of clients endures economic crises easier that allows keeping quality of goods and services up to standard.

The main strategic advantages in general obtained from service are [2]:

$\checkmark$ concentration on increase in competitiveness, satisfaction of needs of clients and development of technologies, carrying out optimum reengineering, stable increase in overall performance of the company by continuous improvement of key indicators of work, profitability, including due to release of internal resources, reduction of investments into non-basic funds; $\checkmark$ cutting of costs for the business functions transferred to service is reached due to specialization of the service company in narrow area and also to scale effect, that leads to decrease in costs in comparison with a complex of expenses, including tax and social, on creation and support of regular jobs;

$\checkmark$ improving quality and reliability the functions transferred to service, since when solving similar tasks, service companies accumulate experience and can introduce modern technologies at the customer enterprise, use specialized equipment and highly qualified personnel content whose use which is not rational in the client's environment;

$\checkmark \quad$ division and transfer of risks due to use performer of the competition forcing mechanisms to react market changes flexibly, to increase efficiency by internal processes optimization.

Positive results to transfer maintenance and repair of company equipment to service organization are:

- transparency and optimization costs of maintenance and repair equipment;

- idle times reduction (increase in productivity) of the equipment;

- existence of guarantee certificates from the service organization;

- quality production improvement (decrease in level of marriage and inadequate quality production cause of unsatisfactory technical condition equipment);

- quality improvement of the rendered services.

Maintenance of reliability characteristics equipment of which has developed a settlement resource up to standard is possible only at the rational organization of his service (capital repairs, modernization and so forth) as his fast replacement by the new equipment isn't feasible for the economic reasons.

Such situation will remain long enough. In general input rates of new power objects will hardly advance growth rates of energy consumption, and in a number of regions become a limiting factor of further economic development today. Thus, service system improvement of electric equipment is one of components of a common problem of increase in reliability of power supply in general. At the same time improvement process in the conditions of sector restructuring breaks up to a number of tasks interconnected among themselves.

Reliability by the following factors is influenced:

1. Loss quality of maintenance and repair;

2. Violation of the rules of operation and technology of repair;

3. Design flaws;

4. Aging, wear;

5. Transition processes;

6 . Weather conditions (working conditions);

7. Temperature drops.

The modern equipment allows creating the interactive control system which isn't demanding special dispatching divisions. In this case the automated system is on a continuous communication with the engineeroperator, allowing him to monitor work online and if necessary reporting about probable failures on a pager or the mobile phone. It substantially facilitates service and systems control. At the majority of companies, technical regulations include planned preventive maintenance (hereinafter referred to as "PPM") of complex equipment. Usually it is caused by the fact that repair cost upon accident significantly (sometimes up to 10 times) is more expensive than PPM. At the same time the principle of planned character assumes preventive orientation of a stop and equipment repair [3].

Such service system of the complex equipment consists that by means of constant technical diagnosing the analysis of a condition of knots and the unit in general is made and the forecast of necessary maintenance and repair becomes. At the same time diagnosing by various criteria can be made. It is the simplest to organize control on change of admissible level of one or several parameters. More difficult options include not only admissible size of parameter control, but also forecast of level of reliability knot or the unit in general.

The main complexity maintenance and repair on actual state consists in the organization of collecting and data processing at equipment operation. Despite presence at a considerable part of the systems complex equipment allowing automating all processes not everywhere it becomes, and not any organization is capable such system organize. However, serious producers usually with great attention treat service of the production. It is possible to claim that what the manufacturing firm is better known that has better organized service and the more opportunities for the professional service organization on actual state.

In particular service model cardinally solves different problems of the power company:

- ensuring full readiness of the operation equipment during all term of stay him at the consumer (production aspect);

- consultation of potential consumers before allows services of the power company by them allowing to make him a conscious choice; collection of information how service at "competitors" - a benchmarking is organized; analysis of claims (marketing aspect); 
- $\quad$ training personnel of the power company for the most effective and safe operation of the acquired equipment (the training aspect);

- $\quad$ expeditious delivery of spare parts and contents purpose necessary network of warehouses, close contact with manufacturers of the equipment and accessories (logistic aspect);

- methodical ensuring service activity and recommendations regarding improvement of services development; introductions of technological innovations (innovative aspect).

\subsection{Model service organization}

\subsubsection{Service model (example of Federal Grid Company of Unified Energy System)}

The basic (autotransformers, transformers, reactors, gasinsulated switchgear, gas-insulated circuit breakers, etc.) and auxiliary (compressors, rechargeable batteries, etc.) the equipment with estimated long (more than 3 years) operation term on objects is transferred to service.

Main objectives of service of the equipment of PJSC "FGC UES": [2]

- increase in reliability of the equipment in the conditions of optimization of costs maintenance and repair (improvement of quality maintenance and repair);

- achievement of economic effect;

- need of extension of the guarantee certificates for the equipment issued by manufacturer at supply of equipment (for the new equipment), and establishments of guarantee certificates of manufacturer for the equipment on which works within service are performed (for the equipment with last warranty period).

In agreeing the model of services for PJSC FGC UES, the following features have been taken into consideration:

- diversity of the equipment installed, most of which no longer has the factory warranty, and a considerable portion has been in operation beyond its specified life;

- highest requirements concerning the emergency response in the event of damage to equipment or devices (speed of emergency response) to ensure stable operation of the UNEG;

- sufficient number of skilled in-house personnel, for many years performing repair and diagnostics of equipment and ready to improve their skills, master new equipment, and perform simple repairs;

- availability of the affiliate specialized in repair and complex diagnostics of equipment - JSC Specialized grid service company Unified national electric grid (JSC Elektrosetservice UNEG), staffed with qualified personnel and modern technological equipment;

- geographical distribution of the UNEG facilities in the territory of 73 constituent entities of the Russian Federation, which complicates the creation of factory service centers that would meet the requirements of emergency preparedness;

- the network of branches of PJSC FGC UES and JSC Elektrosetservice UNEG, covering almost the entire territory of Russia, which is an additional argument in favor of bringing their own staff to perform certain types of work within the service after its training and certification.

Given these peculiarities, PJSC FGC UES organizational document has been approved and will act as a model service organization:

1. Execution of service in the format of bilateral contract between the Customer and the Contractor. The contractor may be the organization is the manufacturer of equipment (devices) or his official representative on the territory of the Russian Federation with authorization for the supply of spare parts and provision of services, with the implementation of certain types of works in the justification and agreement with the Customer by the certified personnel of the Subcontractor. As part of a pilot implementation of the service model PJSC FGC UES in 2010 and 2011. Contracts were signed for execution of works on maintenance with the leading companies-manufacturers of the electrotechnical equipment. Pilot projects on implementation the service models found to be successful.

2. The first experience of outsourced service made by a number of key domestic and foreign manufacturers of electrical equipment allowed to carry out the analysis of this model and its adjustment for the transition to the long-term form of service (5 years).

The development of the concept of service at the facilities of PJSC "FGC UES": [3]

A) Contract for service compressor equipment service -797 compressors was transferred for service;

-equipment inspections by representatives of the manufacturer are organized;

-an overhaul of the 231 pieces of compressors.

B) Contract for service maintenance of electrical equipment manufactured by $\mathrm{ABB}$

-training of Customer's personnel (122 people) in the service training center with the issuance of certificates;

- creation of emergency reserve circuit breakers;

-15 switches have been overhauled;

-supply of spare parts;

-reducing the time of emergency recovery operations.

\section{Conclusions}

Introduction of the equipment service model aimed at improving the quality and efficiency of maintenance and repair in terms of cost optimization is one of the most important areas of activity for PJSC FGC UES, where a positive effect has been achieved.

The results obtained in the implementation of the equipment service concept of PJSC FGC UES are:

- extension of warranty issued by the manufacturer;

- ensuring the participation of manufacturers of the main equipment in the maintenance of its normative status throughout the life cycle;

- availability of emergency supplies close to the UNEG facility warehouses, taking into account the recommendations of manufacturers of equipment; - minimum time for the elimination of faults due to the availability of the necessary resources (qualified personnel and emergency reserve warehouses) and 
guaranteed services of the chief engineer of the manufacturer;

- improving qualifications of own maintenance personnel.

In general, the transition to the approved model of service in PJSC FGC UES has shown its transparency and the availability of a mechanism of control over investments and the resulting effect, which is a decisive factor in the development of the industry as a whole.

\section{References}

[1] B.A. Raizberg, L.S. Lozovsky, E.B. Starodubtseva "Modern economic dictionary" (2nd ed., rev. M.: INFRA-M, 1999)

[2] Order of JSC FGC UES dd. 19.10.2015 no. $410 / 349$ "On adopting the Regulation on service of equipment of PJSC FGC UES"

[3] Y.V Zhilkina "Organization of service in the electricity industry" (Special issue of the journal ELECTRICITY. Transmission and distribution (No. 2(5) June 2017) for JSC “Rosseti”) 